\section{An Applicable Method for Elaborating Agricultural Logistics Trends}

\author{
Szabolcs Duleba \\ College of Nyíregyháza, \\ Faculty of Economic and Social Sciences, \\ Department of Logistics and Project Management, Nyíregyháza \\ duleba@nyf.hu
}

\section{SUMMARY}

Hungarian scientific practice focuses mainly on statistical methods to elaborate sector-specific trends. This paper aims to offer another alternative. The author's view is that in rapidly and significantly changing markets, data extrapolation is not necessarily the ideal way to forecast certain trends of the sector. Agricultural Supply Chains have been restructured lately. There are remarkable developments in fields such as: warehousing systems, telematic systems, transportation. This is one of the reasons several drivers may alter the trends determined previously by statistical professionals. AHP (Analytic Hierarchy Process) synthesizes expert opinions concerning the future, so it is a decision-supporting method and therefore more flexible to the changes of the sector. The author introduces the application of the AHP for Agricultural Logistics Trends.

Keywords: Agricultural Supply Chains, trends, AHP, logistics solutions

\section{INTRODUCTION}

Thinking in supply chains is becoming increasingly popular in agriculture. The participants in the sector have been realising that the competition is rather among chains than companies (Chikán and Demeter, 1999). Unfortunately, most actors in Hungarian agriculture lack such realisation. Without fitting into International and European trends Hungarian companies may lag behind and lose their competitiveness.

Very thorough and representative research was carried out by several European universities in 2000, within the SULOGTRA project. In 1998, the European Commision set up a research program called „Compatitive and Sustainable Growth" which was one of the four thematic programs of the $5^{\text {th }}$ RTD Framework Program (1998-2002). SULOGTRA was, among others, one of the research projects, belonging to this program. The main objectives of the project were twofold. On the one hand, to analyse the effects of current trends in logistics and supply chain management on the transportation system. On the other hand, it was to assess opportunities improving supply chain performance.

The project began in January 2000, and lasted for two years. To assure a European perspective on the subject research, institutes and consultancy organizations from almost all of the EU 15 countries were involved in the project (eg. Netherlands Economic Institute, Templeton College, Heriot-Watt University, Louis Berger S.A., TRANSLOG, TIS, and the Technische Universitaet Berlin as project coordinator). The researchers asked over 400 logistic experts their opinions on the topic. Agriculture was among the examined sectors, as part of the FMCG (Fast Moving Consumer Goods) sector.

In Hungary, such a research has not been carried out. The author of this article, Szabolcs Duleba has been working on it with the help of Dr. Zoltán Szegedi and Dr. Zoltán Bokor. The data are still being collected, but the applied method and the process of the analysis is worth of publication.

\section{RESEARCH METHODOLOGY}

The elaboration of sector-specific trends based on expert opinions demands the construction of a suitable questionnaire. Our basic principle is the following: creating future trend scenarios is too complex for a single evaluator. It is less difficult to judge the relative importance of the influencing factors and to estimate the alternative changes of these factors. If we synthesize many experts' evaluations, we can get a more proper future scenario.

Before making the questionnaire, a very thorough preliminary survey must be done on the identification of sector-specific trends. Afterwards, we identify for each trend criteria influencing the trend. Finally, we determine alternative levels of trend change.

Afterwards it is possible to ask the evaluators about the relative importance of the influencing factors and the possible change of the factors in the given time horizon. The results are determined by the AHP.

The AHP method itself contains the following steps (Figure 1).

The chosen scientific method is the AHP (Saaty, 1980), because of the following:

$\checkmark$ It provides a practical way to deal quantitatively with complex decision-making problems

$\checkmark$ It provides weight-assignment features

$\checkmark$ It offers the ability to provide sensitivity features

$\checkmark$ It offers the potential for „rank reversal” when similar/identical alternatives are introduced

$\checkmark$ It features lateral/hierarhical criteria analysis However, the disadvantages of the AHP must be mentioned too:

- Subjectivity: All the answers reflect the subjective opinion of the responder expert. Although there are some facts and data that may give help the responder, comparison is quite difficult - even for the person dealing with the specific sector over many years. That is why the survey must be made on a representative basis. 
- Consistency requirement: The AHP supposes that the responder is able to fill in the questionnaire consequently; therefore the elements of the different matrix are all consistent. Because of the large number of pairwise comparisons, it is not easy to answer conveniently all of the time. Thus, the method has a self-checking procedure and indicator: Consistency Ratio. This ratio can be created as follows: the biggest eigenvalue of the matrix/the order of the matrix. In the case this ratio shows an inconsistency, the responder must fill in the table again. If this happens many times, then costs and energy wastige would increase because of the duration of the process.

The AHP is applicable for determining the future logistic trends, because:

- There are several influencing factors

- The main trends can be identified by an expert consensus

- Quantitative and qualitative elements are also part of the analysis

- The sector-specific trends can be ranked by personal opinions

- One can estimate the relative weights of the determining factors, in order to obtain the final trend-importance

- The economic and technical drivers are comparable in the aspect of logistics

- Alternative levels of trend change can be set up

The process of the analysis were the same in the case of the two surveys (EU 15 and Hungary), because the AHP gave the proper steps.

Figure 1: The Analytic Steps

Step-1: Establish Objectives

Step-2: Identify all Relevant and Important Criteria

Step-3: Construct all Criteria into a Hierarchy Structure

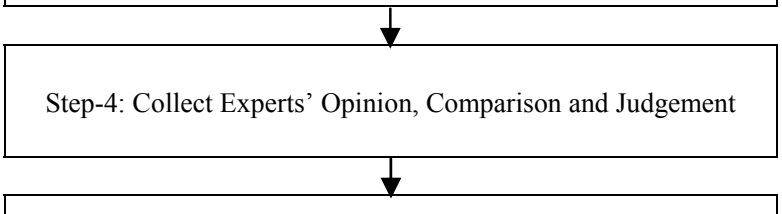

Step-5: Compute Priority Weights and Ratings of Criteria

Step-6: Analyze and Evaluate the Impact of all Criteria

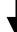

Step-7: Incorporate all Key Criteria into the Determination of Trends

Source: Yang and Shi (2002)

\section{EXPERIENCE OF THE HUNGARIAN RESE- ARCH}

Below, our own research results are introduced on the same topic. Some data are still being processed, but the temporary results may be published. The research was made within the Hungarian food and beverage sector. The main purpose was to identify the most significant trends in both regions (EU 15 and Hungary), to compare them, in order to find out what growth potential can be projected (for the future) for Hungary and for other emerging markets' fast moving consumer goods (FMCG) and agro supply chains.

While the SULOGTRA survey can be regarded as being representative (the synthesis of over 400 experts opinion), it can be used as a benchmark in the comparison between the European and Hungarian results.

We have collected over 20 Hungarian logistic managers' opinion (which will be extended to 50), who are working in the FMCG sector.

Under the conducted surveys, we analyzed companies which were participants of the Food and Beverage Sector. The participants of the European project could afford to ask all the members of certain supply chains, all the companies of logistic networks. Among the evaluators were: company owners, logistic managers, managers and owners of 3PLP's (Third Party Logistic Service Providers).

In the Hungarian research, we decided to visit only those companies which may be regarded as System Integrators in the supply chain. Choosing the suitable responders is one of the key points of using the AHP. The evaluator must have a view of the whole chain, and must be aware of all logistic activities within the chain. Taking these criteria into account, only System Integrator companies are suitable for responding. The supply chain managers, logistic managers and owners have the necessary overview. Within the FMCG sector, multinational retailers can be identified as System Integrators, such as Tesco, Cora, Auchan, Lidl, Spar, not only in Hungary, but also in Europe.

There is a big difference between the two projects. While the EU program started in 2000, we could examine only the 2005-2010 time horizon. This is why the growth rates of the Hungarian studies should be considered more carefully, and proportionally to the 10 year time span. We did not make the comparison prior to 2005 between the SULOGTRA predictions and reality on purpose, because this is included in the Hungarian experts' opinions.

Because the Hungarians listed fewer important trends, the questionnaire was reduced to the examination of 4 trends.

In the Hungarian survey, the relevant trends named by the experts are:

- Spatial concentration of production

- Development of break-bulk transhipment systems

- Rationalization of the supply base

- Decreasing direct delivery

The Table 1 shows the difference between the SULOGTRA and the Hungarian surveys' results. 
Most important logistics trends of the food and beverage sector

\begin{tabular}{|c|c|}
\hline EU 15 & Hungary \\
\hline Spatial concentration of production & Spatial concentration of production \\
\hline Spatial concentration of inventory & MISSING \\
\hline Development of break-bulk systems & Development of break-bulk systems \\
\hline Rationalisation of the supply base & Rationalization of the supply base \\
\hline Decreasing direct deliveries & Decreasing direct deliveries \\
\hline Application of time compression principles & MISSING \\
\hline Growth of ,nominated day” deliveries & MISSING \\
\hline Reverse logistics & MISSING \\
\hline
\end{tabular}

Source: Own development

After having completed the AHP process by counting the final weights of the components and determining the Consistency Ratio, the conclusions are as follows:

$>$ A measurable increase of spatial concentration of production (supported by the networks infrastructure integration and the regulations harmonisation)

$>$ A high increase of break-bulk transhipment sytems (supported by the expected increase in standardization of vehicles and communications, as well as by the integration of technologies)

$>$ A substantial increase in rationalization of the supply base (supported by the standardisation of goods and their movement and by the network infrastructure integration)

$>$ A low decrease of direct deliveries (mainly supported by the insufficent advancement and integration of technologies)

The Table 2 includes the expected changes by 2010 in the sector.

Change scenarios of the relevant trends. Increase by 2010

\begin{tabular}{|l|c|c|}
\hline \multicolumn{1}{|c|}{ Trend } & EU 15 & Hungary \\
\hline Spatial conc. of production & LOW & MEASURABLE \\
\hline Break-bulk systems & MEASURABLE & HIGH \\
\hline Rationalisation of supply base & LOW & MEASURABLE \\
\hline Decreasing direct deliveries & MEASURABLE & LOW \\
\hline
\end{tabular}

Source: Own development

In the Hungarian survey, the most influential trend was named as the development of break-bulk transhipment systems, followed by the spatial concentration of production. According to the evaluators, these two trends have got the biggest growth potentional in the countries' supply chains. The direct deliveries will decrease only sligthly, by 1 percent, by 2010 .

\section{CONCLUSIONS}

We can conclude that Hungarian market demands are still differ from the European benchmark. Unfortunately, the demand for the reverse logistics is not transparent yet, although the principles of the European Union are ,alive" in the country. It can be a very significant advantage for the whole agricultural supply chains to apply the solutions of reverse logistics as soon as possible.
The ,rationalisation of the supply base”, and the „spatial concentration of production" can be a menace to the small farms of the country. Without horizontal integration, Hungarian farmers will not be convenient and reliable partners for multinational companies in the sector. The shift from competition to strategic partnership - in a competitive market means a great challenge for people involved directly in agriculture.

Constructing and applying break-bulk systems is a very significant logistics trend, not only in Western Europe, but also in Hungary. From a macro-logistic aspect, Hungary is very well situated. Both the Eastern-Western and Northern-Southern line of transhipment are penetrating the country, especially TEN (Trans European Network) corridor No. 4 and 5 which provides logistics tasks. This is why logistics service centers (LSC), and break-bulk systems were established in the country, although there is 
demand for more (Szegedi, 2006). Undoubtably, logistics experts have already been aware of the importance of these devices.

The missing trends in the Hungarian survey (reverse logistics, spatial concentration of inventory, application of time compression principles, growth of nominated-day deliveries) show clearly that the demands of the Hungarian FMCG sector differ to a certain extent from European market expectations. In the case the sector's participants become more familiar with European trends and try to fulfil demands that have not yet been discovered by the companies and by the consumers themselves, then it could result in a great growth potential for the national FMCG.

\section{REFERENCES}

Chikán, A.-Demeter, K. (1999): Az értékteremtő folyamatok menedzsmentje. Aula Könyvkiadó, Budapest, 383-389.

Saaty, T. L. (1980): The Analytic Hierarchy Process. New York, NY: McGraw-Hill International

Szegedi, Z. (2006): Logistics Management Awareness of Hungarian Small- and Mid-Size Companies, in: "Competitiveness in the EU - Challenge for the V4 Countries". Proceedings of the International Scientific
Conference, May 17-18, 2006. Nitra, Slovakia, 165-172. ISBN 80-8069-704-3

Yang, J.-Shi, P. (2002): Applying Analytic Hierarchy Process in Firms' Overall Performance Evaluation: A Case Study in China International Journal of Bussines, 7.

SULOGTRA - Effect on Transport of Trends in Logistics and Supply Chain Management, EU 5th FP, 2000-2002 